\title{
Antitrypanosomal Effect of Hydromethanolic Extract of Solanum anguivi Lam on Field Isolates of Trypanosoma congolense Infected Mice
}

\author{
Debela Abdeta $\mathbb{D}^{1},{ }^{1}$ Solomon Mequanente Abay $\mathbb{D}^{2},{ }^{2}$ Mirutse Giday, ${ }^{3}$ Nigatu Kebede, ${ }^{3}$ \\ and Getechew Terefe ${ }^{4}$ \\ ${ }^{1}$ School of Veterinary Medicine, Wollega University, Nekemte, Ethiopia \\ ${ }^{2}$ School of Pharmacy, Addis Ababa University, Addis Ababa, Ethiopia \\ ${ }^{3}$ Akililu Lama Institutes of Pathobiology, Addis Ababa University, Addis Ababa, Ethiopia \\ ${ }^{4}$ Department of Parasitology, Addis Ababa University, Bishoftu, Ethiopia
}

Correspondence should be addressed to Debela Abdeta; debela.abdeta@gmail.com

Received 26 June 2021; Accepted 9 December 2021; Published 29 December 2021

Academic Editor: Bernard Marchand

Copyright (C) 2021 Debela Abdeta et al. This is an open access article distributed under the Creative Commons Attribution License, which permits unrestricted use, distribution, and reproduction in any medium, provided the original work is properly cited.

\begin{abstract}
Introduction. Trypanosomiasis is one of the world's most serious infectious diseases caused by Trypanosoma parasites. Concern about resistance to conventional antitrypanosomal drugs, mosquito vector resistance to existing insecticide side effects of existing antitrypanosomal drugs justifies the urgent need for more effective, tolerable, and affordable drugs. Objective. The present study is aimed at determining the in vivo antitrypanosomal effect of the hydromethanolic extracts of Solanum anguivi fruit extracts against the field isolates of T. congolense. Methods. The $80 \%$ methanol extracts of $S$. anguivi fruits were prepared by cold maceration technique. In vivo curative tests were done to check the effect of plant extract against T. congolense in Swiss albino mice. Plant extracts were administered at doses of 100,200 , and $400 \mathrm{mg} / \mathrm{kg} / \mathrm{body}$ weight. Acute toxicity of the extracts at $2000 \mathrm{mg} / \mathrm{kg}$ was performed according to OECD guidelines. Data obtained from the experiment were analyzed using one-way ANOVA followed by Tukey test. Results. This study indicated that extract did not exhibit any sign of acute toxicity up to $2000 \mathrm{mg} / \mathrm{kg} / \mathrm{body}$ weight. In curative test, extracts reduced parasitemia, preventing the drop in packed cell volume and body weight significantly $(p<0.05)$, compared to control. Groups provided with the extract before infection got prolonged incubation period with chemoprophylactic effect at the doses of 100,200 , and $400 \mathrm{mg} / \mathrm{kg}$. Phytochemical analysis showed presence of flavonoids, steroids, triterpens, saponins, glycosides, tannins, and alkaloids. Conclusion. The extract showed promising curative. Further effort is required to isolate and purify specific compounds responsible for antitrypanosomal activity of studied plant.
\end{abstract}

\section{Introduction}

Trypanosomes are protozoan parasite affecting both human and livestock. It is mainly found in Tropical Africa, Latin America, and Asia. It produces serious disease in human being such as sleeping sickness caused by T.b.rodensia and T.b.gambesie in Africa and Chagas disease caused by T. cruzi causes in Americas. In endemic areas, the other species of Trypanosoma affect animals and produce enormous economic impact [1]. African animal trypanosomiasis (AAT) is the most common diseases of covering 37 sub-Saharan countries located between latitudes $14^{\circ} \mathrm{N}$ and $29^{\circ} \mathrm{S}$ and about
9 million $\mathrm{km}^{2}$ land area [2]. This highly fatal protozoan disease is virulent and inoculable but not contagious (except dourine, a venereal trypanosomiasis of equines). African animal trypanosomiasis is responsible for 3 million livestock and 55,000 people death annually in agriculture and mixed farming system environments thus making it an important priority for the agricultural sector and biomedical and public agencies [3].

Current trypanosomiasis control relies on trypanocidal drugs, use of trypanotolerant cattle breeds, and controls of the vector, namely, the tsetse fly. None of these methods have the full potential to work in the long-term control of 
the disease. Most heavily relied on are the trypanocidal drugs, and this has led to an increasing problem of resistance in the target organisms [4]. Therefore, the search for new chemical entities that should be effective against all species of trypanosomes and safe and affordable for diseaseendemic countries is the best choice left option to fight against the notorious impact of bovine trypanosomiasis on cattle productivity [5] and to reduce human loss due to human trypanosomiasis.

To control trypanosomiasis, researchers are seeking to find some alternative source of medications from natural sources due to the possible side effects of the existing drug [6]. Many herbal extracts like Azadirachta indica, Acacia albica, Achyrocline and Indigofera oblongifolia [7] Khaya senegalensis, Piliostigma reticulatum, Securidaca longepedunculata, Ximenia Americana, and Artemisia abyssinica [8-10].

These are found in plants which are potential sources of new drugs since they contain countless numbers of molecules that have pharmacological effects [11]. Solanum anguivi lam (local Afan Oromo name: "Hiddii seexanaa") is a rare ethnomedicinal herb that belongs to the family Solanaceae and can be found throughout the nonarid parts of Africa. S. anguivi have been recognized to possess medicinal properties, and their use in traditional systems of medicine has been on record for a long time. It is highly polymorphic and variable in its plant structure, fruits, and leaf characters [12]. Although the plant is in use for the treatment of trypanosomiasis in Ethiopian, there is no laboratory-based evidence for the effectiveness and safety of the plant [13, 14]. Therefore, the study was carried out to determine the in vivo antitrypanosomal effect of hydromethanolic extract of $S$. anguivi fruit on mice experimentally infected with a field isolate of $T$. congolense.

\section{Materials and Methods}

2.1. Plant Collection and Authentication. In this study, Solanum anguivi fruits collected from Wayu Tuka district as of November 2015 were used as potential antitrypanosomial agent. Leaves with flower spacemen of the plant were collected, identified, and authenticated at Aklilu Lema Institute of Pathobiology, and the vouchers were deposited at the National Herbarium of Addis Abba University with number DA 02.

2.2. Preparation of Plant Extract. Dried powder of the plant material was macerated in $80 \%$ methanol in an Erlenmeyer flask for 72 hours at room temperature and periodically shaken with a mini orbital shaker. It was filtered twice with gauze and Whatman filter paper No. 1. Supernatants from the agitated material were separated from the undissolved portion. Using a rotary evaporator, methanol was removed from the filtrate. To remove water, the filtrate was lyophilized.

2.3. Ethical Approval. Ahead of starting data collection, ethical clearance was taken from research ethics committee (REC) of School of Veterinary Medicine, Wollega University, dated 15/09/2016 with minute no. SVM.RERC/004.
2.4. Experimental Animals. Swiss albino mice of either sex are weighing 30-35g (age 10-12 weeks). They were purchased from Ambo University, bred in ALIPB's laboratory animal unit, and used for this study. A standard animal diet was fed to them, and they were watered frequently. They were fed with standard animal feed and watered ad libitum and maintained at room temperature of $23-25^{\circ} \mathrm{C}$ with a relative humidity of $60-65 \%$. All procedures complied with the Guide for the Care and Use of Laboratory Animals [15].

2.5. Test Organism and Its Maintenance. T. congolense was obtained from Addis Ababa University Department of Veterinary Parasitology by infecting white albino mice intraperitoneally. Mice were screened for development of infection using buffy coat or Murray method [16].

2.6. Experimental Design. Thirty mice of male and female were randomly grouped in to five groups (I-V). All groups were injected with $T$. congolense $\left(5 * 10^{5}\right.$ parasites $\left./ \mathrm{ml}\right)$ infected blood. Groups I and II were administered Diminazene aceturate @3.335 mg/kg intraperitoneally, respectively, to serve as untreated and treated control whereas groups III-V administered at daily dose of 100, 200, and $400 \mathrm{mg} /$ $\mathrm{kg}$ for consecutive 7 days from 10th day postparasite inoculation. Parasitemia and PCV were observed every 4 days for 21 days while body weight and rectal temperature were monitored every 2 days. Mean survival time was monitored for 6 weeks [17].

2.7. Parasitemia Determination. Parasite infected mice were checked for parasitemia every four days beginning on the tenth day after infection. The parasitemia of mice was monitored by microscopy at a magnification of $40 \mathrm{x}$ of blood obtained from the tail and examined by Herbert and Lumsden [18] formula using their rapid matching method. The method involves microscopically counting parasites per field in blood without diluting it. Logarithmic values of this count were obtained by matching with table of Herbert and Lumsden [18]. Monitoring of parasitemia was performed every four days to reduce stress on experimental animals until 21st days posttreatment initiation [19].

2.7.1. Packed Cell Volume Determination. A microhaematocrit centrifuge and a microhaematocrit tube reader were used to determine PCV. PCV was performed every four days until 21st days posttreatment initiation [20,21].

2.7.2. Determination of Body Weight. A sensitive digital weighing balance was used to determine body weights of each mouse in each group on the day of parasite challenge, the day of treatment initiation, and every other day for 21 days [22].

2.7.3. Rectal Temperature Determination. Digital thermometer (Mettle Toledo, Switzerland) was used to determine body temperature on the day of parasite inoculation, treatment commencement day, and every other day for 21 days [20].

2.7.4. Mean Survival Time Determination. Survival rate of each mouse was recorded, and average life was determined for both treatment and control groups [8, 23]. 
2.8. Phytochemical Screening. Presence of plant secondary metabolite was assessed according to the methods described by different scholars.

Saponin, glycosides, tannins, and phlobatannins were carried out as described by Evans [24].

Terpenoid and steroids were carried out according to Briggs [25].

Tests for alkaloids and phenols were carried out according to $[26,27]$ where as flavonoid test was carried out according to Dermarderosian and Liberti's description [28]. The presence of anthroquinones was conducted as describe by [29] for free anthraquinone and combined anthroquinones.

2.9. Acute Toxicity of Crude Extract Determination. The median lethal doses $\left(\mathrm{LD}_{50}\right)$ in mice were determined according to Lorke [30] method and organization for economic cooperation and development (OECD) guide line for testing of chemicals number 420 [31] on Swiss albino mice of female sex weighing 30-35 g and 10-12 weeks' age. The limit dose of $2000 \mathrm{mg} / \mathrm{kg}$ body weight was orally administered sequentially to five female mice and observed for 24 hours and then for additional 14 days. Toxicity signs like changes in physical appearance, behavioral changes and feeding activities, hair erection, lacrimation, reduction in motor, and other signs of acute toxicity and mortality were observed and recorded.

2.10. Statistical Analysis. Statistical Software Package for Social Science (SPSS) was used for data analysis. Data were presented as mean \pm SEM. Significance was determined at 95\% confidence level. Analysis of variance (one-way ANNOVA) was employed to test statistical difference with in all groups. $p$ value less than 0.05 was considered statistically significant.

\section{Results}

3.1. Acute Toxicity. There was no death recorded $200 \mathrm{mg} / \mathrm{kg}$ body weight of the extract. Moreover, there were no gross behavioral changes and sign of toxicity during observation period which is monitored according to OECD 2001 guideline.

3.2. Effects of Hydromethanolic Extract S. anguivi Fruit Treatment on Parasitemia of T. congolense Infected Mice. Preliminary screening for antitrypanosomal activity of hydomethanolic extract of $S$. anguivi revealed none of them completely cleared the Trypanosoma from the blood of infected mice. The pretreatment mean parasite count for all groups was around antilog 8.01 parasite $/ \mathrm{ml}$ of blood. The changes observed in the level of parasitemia of infected treated mice were shown in Figure 1. Treatment with hydromethanolic extract of S. anguivi at 100 and $200 \mathrm{mg} / \mathrm{kg}$ showed a statically significant $(p<0.05)$ reduction in the level of parasitemia with in day 8 to day 12 posttreatment when compared with $400 \mathrm{mg} / \mathrm{kg}$ body weight.

Relapse was recorded for all treatment and positive control groups in which parasite started to be highly detected in the blood of infected mice. There is statistically significant association $(p<0.05)$ in parasitemia between those in $100 \mathrm{mg} / \mathrm{kg}$ of $S$. anguivi compared to all existing groups on days 8 and 12 posttreatment.

3.3. Effects of Hydromethanolic Extract S. anguivi Fruit Treatment on Packed Cell Volume of T. congolense Infected Mice. Groups of mice treated with 100, 200, and $400 \mathrm{mg} / \mathrm{kg}$ of $S$. anguivi and DA3.35 mg/kg showed statistical significance $(p<0.05)$ improvement in PCV measurement on day 4 posttreatment initiation compared with untreated control. Groups of mice treated with 200 and $400 \mathrm{mg} / \mathrm{kg}$ of S. anguivi and DA3.35 mg/kg showed statistically significant $(p<0.05)$ improvement in PCV measurements on day 12 to day 16 posttreatment initiation compared with groups treated with $100 \mathrm{mg} / \mathrm{kg}$ body weight (Figure 2).

3.4. Effects of Hydromethanolic Extract of S. anguivi Fruit Treatment on Body Weight of T. congolense Infected Mice. The mean body weight for S. anguivi indicates that there is a gradual increase through day 0 -day 12 posttreatment for all treatments with a gradual decrease for untreated control at which all animals in the last group and before day 7 posttreatment. The result indicates that the groups treated with higher doses and DA showed higher mean body weight than that of $100 \mathrm{mg} / \mathrm{kg}$ body weight, in which the last group showed a slight decrease in body weight until all animals of the group died at day 18 posttreatment (Figure 3).

3.5. Effects of Hydromethanolic Extract of S. anguivi Fruit Treatment on Rectal Temperature of T. congolense Infected Mice. Throughout the experiment, the rectal temperatures of the animals fluctuated. In the period of follow-up, no differences have been observed (Figure 4).

3.6. Effects of Hydromethanolic Extract of S. anguivi Fruit Treatment on the Survival Period of T. congolense Infected Mice. Death in vehicle (nontreated mice) started 2 days' posttreatment initiation in all mice in which all mice end at $14.83 \pm 0.48$ whereas survival time infected mice treated with $S$. anguivi fruits continues $41.83 \pm 1.17$ days, respectively. Maximum survival period was recorded with DA $3.35 \mathrm{mg} / \mathrm{kg}$ and S. anguivi fruits $400 \mathrm{mg} / \mathrm{kg}$ body weight. The mean survival time of all groups treated with extract and $\mathrm{DA} 3.35 \mathrm{mg} / \mathrm{kg}$ showed that statistical significance $(p<0.05)$ increases in survival days compared with those not treated (untreated control) where higher dose of the extract and DA treated mice showed statistical significance $(p<0.05)$ increase survival days as compared with those groups treated with $100 \mathrm{mg} / \mathrm{kg}$ body weight (Table 1).

3.7. Phytochemical Screening. Phytochemical screening showed the presence of various phytochemicals in the extracts. It was found that the extracts had phytochemicals like saponins, tannins, phenols, terpenes, flavonoids, glycosides, alkaloids, anthraquinones, steroids, and flavonoids.

\section{Discussions}

In vivo antitrypanosomal effect showed that extract decreased the parasite, increased survival days of extract 


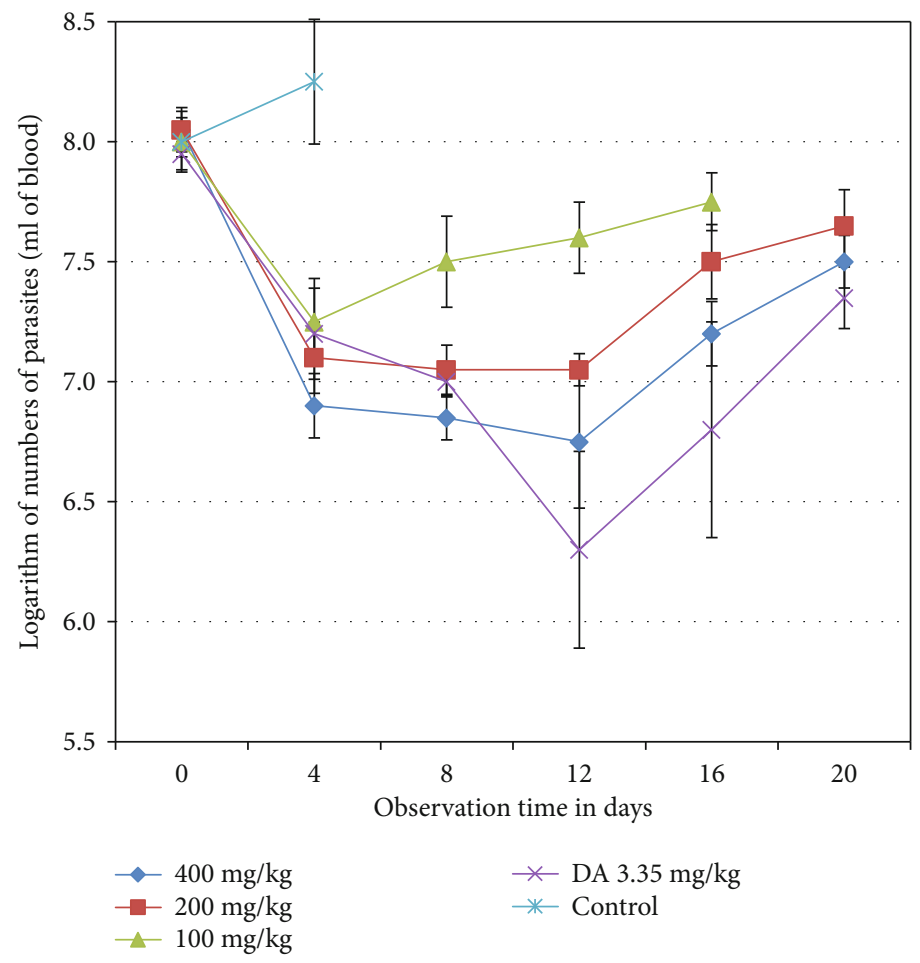

FIGURE 1: Effect of S. anguivi fruit extract treatment on T. congolense infected mice. Values are expressed as mean \pm SEM; day 0: the 10th day after infected blood inoculation.

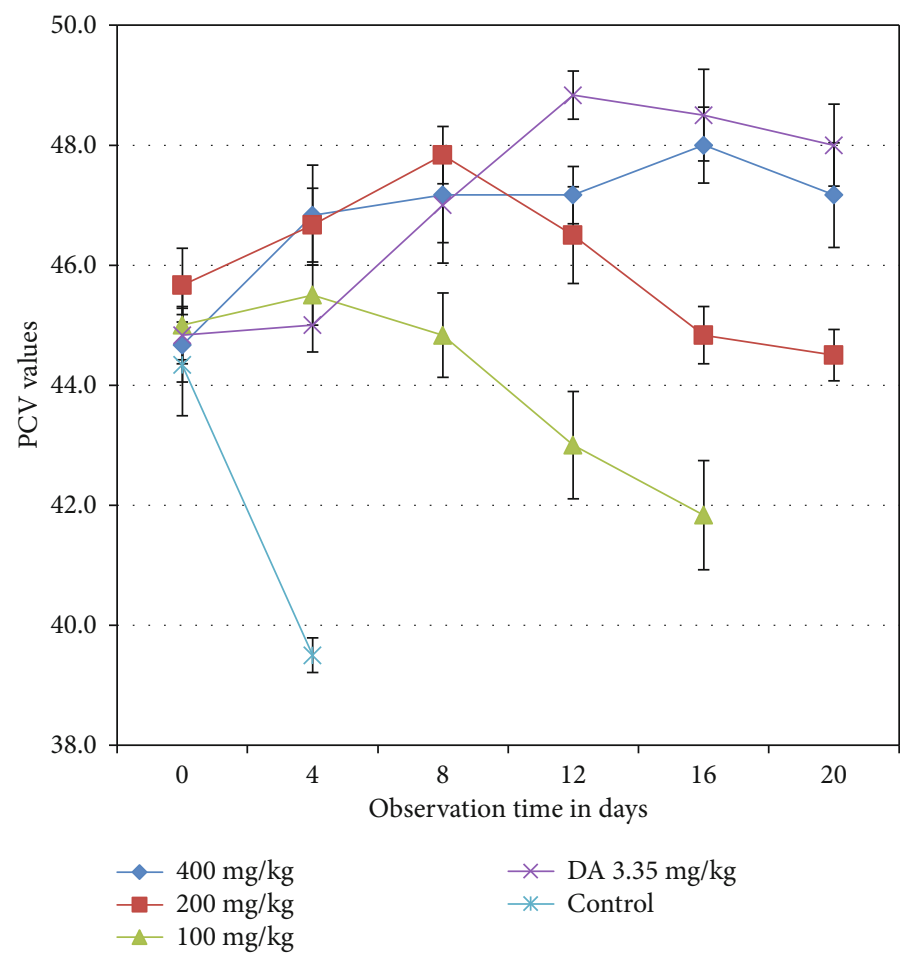

FIGURE 2: Effect of S. anguivi fruit extract treatment on PCV of T. congolense infected mice. Values are expressed as mean + SEM; day 0: the 10th day after infected blood inoculation. 


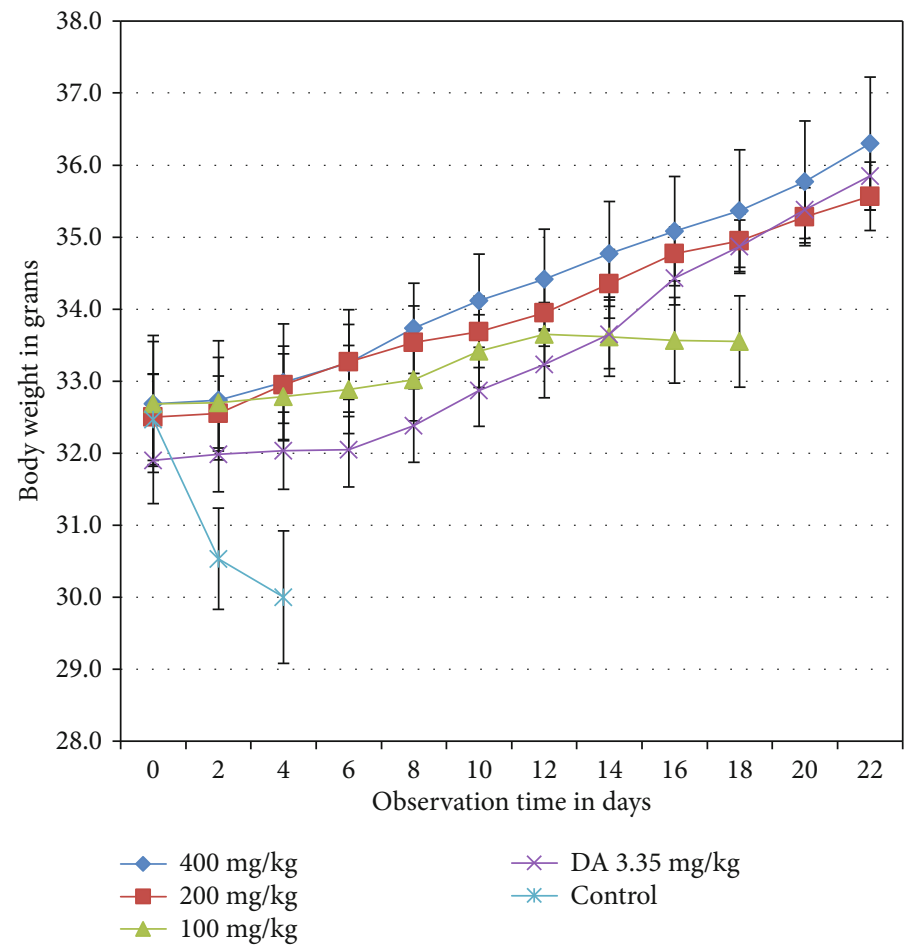

Figure 3: The effect of crude hydromethanolic extracts of $S$. anguivi fruit on body weight of T. congolense infected mice. Values are expressed as mean + SEM; day 0: the 10th day after infected blood inoculation.

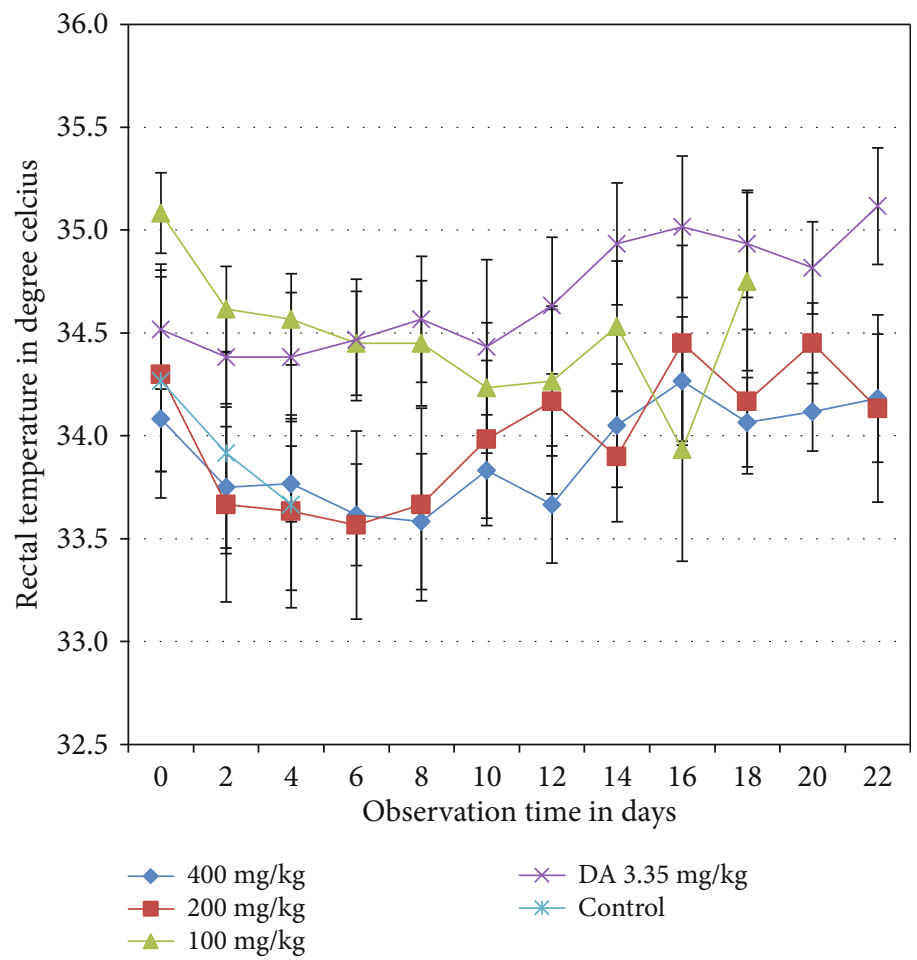

Figure 4: The effect of crude hydromethanolic extracts of $S$. anguivi fruits on rectal temperature of T. congolense infected mice. Values are expressed as mean + SEM; day 0: the 10th day after infected blood inoculation.

challenged and treated mice as compared to the untreated controls. The probable reason that the parasite is decreased in the blood could be as a result of access of the extract to the parasites in the blood. Though the extract fails to eliminate parasite from blood of infected mice, it reduced level of parasitaemia [19, 32-34]. The 
TABLE 1: Effects of hydromethanolic extract of S. anguivi fruit treatment on mean survival time of $T$. congolense infected mice.

\begin{tabular}{lc}
\hline Dose & Mean survival time in days \\
\hline $100 \mathrm{mg} / \mathrm{kg}$ & $31.83 \pm 1.14^{\mathrm{a}}(28.91-34.76)$ \\
$200 \mathrm{mg} / \mathrm{kg}$ & $39.67 \pm .88^{\mathrm{a}}(37.40-41.93)$ \\
$400 \mathrm{mg} / \mathrm{kg}$ & $41.83 \pm 1.17^{\mathrm{ac}}(38.83-44.83)$ \\
DA3.35 mg/kg & $43.00 \pm 1.21^{\mathrm{ac}}(39.89-46.11)$ \\
Control & $14.67 \pm .88(12.40-16.93)$ \\
\hline
\end{tabular}

Values are expressed as mean \pm SEM and $95 \%$ CI (values in bracket); the mean difference is significant at the 0.05 level; control: distilled water; DA: diminazine aceturate. ${ }^{\mathrm{a}}$ Compared to untreated control; ${ }^{\mathrm{c}}$ Compared to $100 \mathrm{mg} / \mathrm{kg}$.

increased survival of $S$. anguivi Lam challenged and treated mice in this study could be related to the action of the active compounds in the extract on red blood cells and/or antioxidant activity.

The current finding is in line with finding of Tadesse et al. [35] who reported that treatment with D. abyssinica extract resulted in level of parasitemia and Kifleyohannes [36] who reported animals treated with A. absinthium and $M$. stenopetala extracts reduced parasite count approximately half that of untreated control [17], and [23] reported that active ingredients from $A$. maciverae and $A$. indica significantly reduce parasitemia with a dose-dependent effect. The current finding indicates that the extract contains some trypanocidal agent that is active for both chemoprophylaxis and chemotherapeutics of the disease.

The result shows that the extract of the plant has the capacity to improve the PCV even if it may decline after relapse of parasites. The relapsing of parasitemia or in ability of the extract to fully eliminate the parasite is related to low amounts of the active compound in the crude extract and also high virulence of the test organism. The mean PCV between standard drug and different doses of the extract were relatively comparable as the findings of Kifleyohannes et al. and Tadesse et al. $[35,36]$. Decrease in mean PCV from untreated controls may be as a result of anemia [19, 37]. The ability to improve PCV is the reason for the long time survival of treated mice. This is possibly by reducing parasite load or in activating the toxic metabolites produced by trypanosome or enhancing resistance of erythrocyte hemolysis $[10,38,39]$. In this study, the results suggest that the ability of extracts to prolong mice's lives could be attributed to their ability to support their antioxidant defense system.

Anemia is a cardinal sign of trypanosome infections. The mechanism of anemia due to this infection is complex and multifactorial in origin. Packed cell volume usually gives an indication of the anemia and status of a trypanosome infected animal [40]. Hepatic injury induced by trypanosomiasis is one of the major health problems to both wild and domestic animals and human beings [7].

The gradual increase in mean body weight for extract treated mice through day 0 to day 12 posttreatment for all treatments with a gradual decrease for untreated control is in agreement with the findings of [41] who reported a slight increase in body weight [8] and who reported treatment with the crude extracts of $Z$. officinale prevented loss of weight associated with parasitaemia [36] also reported that the weight in the untreated infected mice group started to decrease after 12 days' postinfection till the mice died by day 18 where as those on standard drugs and extracts of $A$. absinthium and $M$. stenopetala treated mice generally showed a gradual increase in mean weight until the end of the experimental period. The finding is not in agreement with the reports of [23] who reported that the extract of $A$. indica and suramin-treated groups had a significant decline in body weight.

The extract of S. anguivi fruits was found to contain saponins, tannins, phenols, terpenes, flavonoids, glycosides, and alkaloids. Preliminary phytochemical screening of potent plants against trypanosomes showed the presence of these known bioactive compounds in the crude plant extracts tested [42]. The stem, fruits, roots, flowers, and leaves of $S$. anguivi contain alkaloids, solamargine, and solasoline [43].

It has been known that flavonoids and flavonoid-derived plant natural products are effective antitrypanosomal substances against different trypanosome species $[44,45]$. Phenolics and polyphenols have been reported in the literature to have antitrypanosomal potential by inhibiting the trypanosome alternative oxidase [46]. Saponins from S. anguivi fruits exhibit free radical scavenging activities that possess reducing power, potent antioxidan, and iron chelating ability, making it an excellent candidate in the treatment of diseases in which reactive oxygen species have been implicated [47]. Secondary plant metabolites from S. anguivi extract are able to reduce reactive oxygen species generated during infections, and all parameters of the infected mice were maintained during chemoprophylaxis and chemotherapy.

Acute toxicity study revealed that the extract is nontoxic since no treatment-related signs of toxicity were noticed in the animals throughout the observation period at the dose of $2000 \mathrm{mg} / \mathrm{kg}$, which is in agreement with the results of $[48,49]$. Garner and Clarke [50] had reported that a substance has low toxicity if its LD50 is $1000 \mathrm{mg} / \mathrm{kg}$ body weight. Similarly, Lorke [30] classified substances as slightly toxic if their LD50 ranges from 100 to $1000 \mathrm{mg} / \mathrm{kg}$ body weight. According to Garner and coworkers, any compound or drug with an oral LD50 estimate greater than $1,000 \mathrm{mg} / \mathrm{kg}$ could be considered low toxic and safe [50]. In previous study by Abdeta et al. [51], it was provided that E. kebericho roots have been tested on $T$. congolense infected mice and found effective at crude level with nonobservable toxic level indicating that the claimed ethno medicine was found without acute toxicity at crude level.

\section{Limitations of the Study}

This study was undertaken only on $80 \%$ methanol extract of $S$. anguivi and lacks powerful and deep investigation of its pharmacological qualities with their structural activity relationship.

\section{Conclusions}

Studies on the effects of plant extract on Trypanosoma parasite infection are increasing with promising results. In 
conclusion, the results obtained from this study put evidence that hydromethanolic extract of Solanum anguivi Lam fruits possesses antitrypanosomal activity against field isolates of Trypanosoma congolense. It also provides evidence for traditional use of the plant for management animal trypanosomiasis in Ethiopia. Since current study was carried out on crude extract of the plant, further investigations are needed to identify and isolate pure compound from the plant and determine its mechanism of action.

\section{Data Availability}

The authors will provide all data upon request.

\section{Ethical Approval}

For this work, mice bred at ALPB were provided with food and water; each of them was treated with chemical once. After they are treated with chemicals, result harvested mice are euthanized to end their suffering. During this research, activities respect for animals' dignity were taken. The researcher considers reducing the number of animals used. Natural behavior of individual animals was maintained. The researchers communicated transparently about research findings, sharing of data and disclosing results to community. All samples are collected by trained professionals, and samples are maintained according to national law. Thus, all authors declare that all methods were performed in accordance with relevant guidelines and regulations.

\section{Disclosure}

The authors also acknowledge Research Square for presenting this manuscript part as preprint form.

\section{Conflicts of Interest}

The authors declare that there is no conflict of interest.

\section{Acknowledgments}

Wollega University and Addis Ababa University were acknowledged by the authors.

\section{References}

[1] C. Gutiérrez, M. González-Martín, J. A. Corbera, and M. T. T. Junco, "Chemotherapeutic agents against pathogenic animal trypanosomes," in microbial pathogens, and strategies for combating them: science, technology, and education, pp. 15641573, A. Méndez-Vilas, Ed., Spain, 2013.

[2] R. Mattioli, U. Feldmann, G. Hendrickx, W. Wint, J. Jannin, and J. Slingenbergh, "Tsetse and trypanosomiasis intervention policies supporting sustainable animal-agricultural development," Journal of Food, Agriculture and Environment, vol. 2, no. 2, pp. 310-314, 2004.

[3] K. Mulumba, Socio-economic and agricultural factors in the research and control of trypanosomiasis. PAAT technical and Scientific Series 4, FAO, Rome, 2003.

[4] E. Prowse, Trypanosomosis Disease and Its Control, an Analysis of a New Tsetse-Repellent Technology, Uppsala, 2005.
[5] A. Fromsa, S. Mulaw, and M. Addis, "Study on the prevalence of major trypanosomes affecting bovine in tsetse infested Asosa district of Benishangul Gumuz regional state, Western Ethiopia," Global Veterinaria, vol. 7, pp. 330-336, 2011.

[6] L. V. Kirchhoff, "Trypanosoma species American trypanosomiasis, Chagas' disease: biology of trypanosomes in G.L.," in Principles and Practice of Infectious Diseases, J. E. B. Mandell and R. Dolin, Eds., Elsevier Churchill Livingstone, Philadelphia, $\mathrm{Pa}$, seventh ed. edition, 2009.

[7] M. A. Dkhil, E. M. al-Shaebi, A. S. Alazzouni, S. al-Quraishy, and M. Khalil, "Murine liver response to _Allium sativum treatment during infection induced- trypanosomiasis," Saudi Journal of Biological Sciences, vol. 28, no. 6, pp. 3270-3274, 2021.

[8] T. Feyera, G. Terefe, and W. Shibeshi, "Evaluation of In vivo antitrypanosomal activity of crude extracts of A. abyssinica with T. congolense isolate," BMC Complementary and Alternative Medicine, vol. 14, p. 117, 2014.

[9] S. E. Atawodi, T. Bulus, S. Ibrahim et al., "In vitro trypanocidal effect of methanolic extract of some Nigerian Savannah plants," African Journal of Biotechnology, vol. 2, no. 9, pp. 317-321, 2003.

[10] V. A. Maikai, "Antitrypanosomal activity of flavonoids extracted from X. americana stem bark," International Journal of Biology, vol. 1, no. 3, pp. 115-121, 2011.

[11] D. J. Newman, G. M. Cragg, and K. M. Snader, "Natural products as sources of new drugs over the period 1981-2002," Journal of Natural Products, vol. 66, no. 7, pp. 1022-1037, 2003.

[12] I. G. Adanlawo and M. A. Akanji, "Effect of chronic administration of saponin extract from the fruits of S. anguivi lam on alkaline phosphatase activity of some rat tissues," Nig. J. Bio. Molecul. Biol., vol. 18, no. 1, pp. 59-62, 2003.

[13] M. Megersa, Z. Asfaw, E. Kelbessa, A. Beyene, and B. Woldeab, "An ethnobotanical study of medicinal plants in Wayu Tuka District, East Welega Zone of Oromia Region," Journal of Ethnobiology and Ethnomedicine, vol. 9, no. 68, pp. 2-18, 2013.

[14] A. Shilema, K. Zerom, and A. Mussa, "Ethnoveterinary practices against animal trypanosomiasis in Amoro district, Southern nations, international journal of medicinal research," International Journal of Medicinal Plants Research, vol. 2, no. 7, pp. 238-241, 2013.

[15] ILAR, Institute for Laboratory Animal Research, p. 1996, 1996.

[16] M. Murray, P. Murray, and W. Mcintyre, "An improved parasitological technique for the diagnosis of African trypanosomiasis," Transactions of the Royal Society of Tropical Medicine and Hygiene, vol. 71, no. 4, pp. 325-326, 1977.

[17] A. Ene, S. Atawodi, D. Ameh, C. Nnamani, and Y. Apeh, "Antitrypanosomal effects of petroleum ether, chloroform and methanol extracts of Artemisia maciverae Linn," Indian Journal of Experimental Biology, vol. 47, no. 12, pp. 981-986, 2009.

[18] W. Herbert and W. Lumsden, "Trypanosoma brucei: A rapid "matching" method for estimating the host's parasitemia," Experimental Parasitology, vol. 40, no. 3, pp. 427-431, 1976.

[19] A. Obah, M. Lawal, and Y. Malann, "Anti-trypanosoma activity of the ethanolic leaf extract of Senna occidentalis (Fabaceae) against T. brucei brucei infected mice," International Journal of Basic and Applied Sciences., vol. 2, no. 1, pp. 32-37, 2013.

[20] S. Ngulde, M. Tijjani, J. Ihopo, and M. Ya’uba, “Anti-trypanosomal potency of methanolic extract of Cassia arereh Delile 
root bark in albino rats," Int J Drug, Res Tech., vol. 3, pp. 1-7, 2013.

[21] S. Tasew and R. Duguma, "Cattle anaemia and trypanosomiasis in Western Oromia State, Ethiopia," Revue Méd. Vét., vol. 12, pp. 581-588, 2012.

[22] N. Nweze, B. Anene, and I. Asuzu, "Investigation of the antitrypanosomal activity of Buchholzia coriacea seed extract against a field strain of Trypanosoma congolense," African Journal of Traditional, Complementary, and Alternative Medicines, vol. 8, 5 Suppl, pp. 175-180, 2011.

[23] R. Ngure, B. Ongeri, S. Karori et al., "Anti-trypanosomal effects of A. indica (neem) extract on T. b. rhodesienseinfected mice," Eastern Journal of Medicine, vol. 14, pp. 2-9, 2009.

[24] W. Evans, Trease and Evans' Pharmacognosy, Saunders Ltd., 14th Edition. W.B edition, 1996.

[25] M. H. Briggs, Advances in Steroid Biochemistry and Pharmacology, Academic, New York, 4th ed. edition, 1970.

[26] R. Rafauf, Handbook of Alkaloids and Alkaloid Containing Plants, Academic Press, Wiley, New York USA, 2nd Edition edition, 1970

[27] A. Sofowora, Medicinal Plants and Traditional Medicine in Africa, John Wiley and Sons, Ltd., New York, 1982.

[28] A. Dermarderosian and L. E. Liberti, Natural Products Medicine: A Scientific Guide to Foods, Drugs and Cosmetics, Geo F Stickley Co, Philadelphia, USA, 1st Ed. edition, 1988.

[29] V. Tyler, L. Brady, and J. Robbers, Pharmacognosy, Lea and Febiger, Philadelphia, USA, 9th Edition edition, 1988.

[30] D. Lorke, "A new approach to practical acute toxicity testing," Archives of Toxicology, vol. 54, no. 4, pp. 275-287, 1983.

[31] OECD, Organization for Economic Cooperation and Development guidelines for Testing of Chemicals, Acute Oral ToxicityFixed Dose Procedure, 2001.

[32] E. Mergia, W. Shibeshi, G. Terefe, and T. Teklehaymanot, "Phytochemical screening and in vitro antitrypanosomal activity of aqueous and methanol leaf extract of Verbascum sinaiticum (Scrophulariaceae) against Trypanosoma congolense field isolate," J Clin Exp Pathol, vol. 4, no. 4, 2014.

[33] N. Justina, A. Ibezim, N. Fidele, U. A. Michael, and C. M. John, "Anti-trypanosomal activity of Nigerian plants and their constituents," Molecules, vol. 20, pp. 7750-7771, 2015.

[34] D. Abdeta, N. Kebede, M. Giday, G. Terefe, and M. A. Abay, "In Vitro and In Vivo Antitrypanosomal Activities of Methanol Extract of Echinops kebericho Roots," Evidence-based Complementary and Alternative Medicine, vol. 2020, 2020.

[35] B. Tadesse, G. Terefe, N. Kebede, and W. Shibeshi, "In vivo anti-trypanosomal activity of dichloromethane and methanol crude leaf extracts of Dovyalis abyssinica (Salicaceae) against Trypanosoma congolense," BMC Complementary and Alternative Medicine, vol. 15, no. 1, p. 278, 2015.

[36] T. Kifleyohannes, G. Terefe, Y. Tolossa, M. Giday, and N. Kebede, "Effect of crude extracts of M. stenopetala and A. absinthium on parasitaemia of mice infected with T. congolense," BMC Research Notes, vol. 7, p. 390, 2014.

[37] H. Suliman and B. Fieldman, "Pathogenesis and aetiology of anaemia in trypanosomiasis with special reference to T. brucei and T. evansi," Protozoology Abstracts, vol. 13, pp. 37-45, 1989.

[38] H. I. Inabo and M. M. Fathuddin, "Antitrypanosomal potentials of ethanolic leaf extracts of P. granatum on T. b. brucei infection, Bayero," Journal of Pure and Applied Sciences, vol. 4, no. 2, pp. 35-40, 2011.

[39] A. Wurochekke and G. Anyanwu, "Antitrypanosomal activity of Anogeissus leiocarpus in rats infected with T. brucei brucei," Int Res J, Biotechnol., vol. 3, no. 1, pp. 5-9, 2012.

[40] K. Lelisa and B. Meharenet, "Anaemia associated with trypanosomes infections in cattle of West Gojjam Zone, Northwest Ethiopia," Veterinary Medicine International, vol. 2021, Article ID 5531537, 7 pages, 2021.

[41] P. Kobo, P. Erin, M. Suleiman, H. Aliyu, M. M. S. Tauheed, and M. Mamman, "Antitrypanosomal effect of methanolic extract of Zingiber officinale (ginger) on Trypanosoma brucei brucei-infected Wistar mice," Veterinary World, vol. 7, no. 10, pp. 770-775, 2014

[42] F. Freigburghaus, R. Kaminsky, M. H. N. Nkuna, and R. Brun, "Evaluation of African medicinal plants for their in vitro trypanocidal activity," Journal of Ethnopharmacology, vol. 55, no. 1, pp. 1-11, 1996.

[43] R. N. Chopra, I. C. Chopra, K. L. Handi, and L. D. Kapor, Indigenous drugs of India, Academic publishers, Calcutta, II edition edition, 1994.

[44] S. Hoet, F. Opperdoes, R. Brun, and J. Quetin-Leclercq, "Natural products active against African trypanosomes: a step towards new drugs," Natural Product Reports, vol. 21, no. 3, pp. 353-364, 2004

[45] J. B. Harborne and C. A. Williams, "Advances in flavonoid research since 1992," Phytochemistry, vol. 55, no. 6, pp. 481504, 2000.

[46] Y. Yabu, A. Yoshida, T. Suzuki et al., "The efficacy of ascofuranone in a consecutive treatment on _Trypanosoma brucei brucei_in mice," Parasitology International, vol. 52, no. 2, pp. 155-164, 2003.

[47] O. O. Elekofehinti, J. P. Kamdem, A. A. Bolingon et al., "African eggplant (_Solanum anguivi_Lam.) fruit with bioactive polyphenolic compounds exerts _in vitro_ antioxidant properties and inhibits $\mathrm{Ca}^{2+}$-induced mitochondrial swelling," Asian Pacific Journal of Tropical Biomedicine, vol. 3, no. 10, pp. 757-766, 2013.

[48] F. Shiferie and W. Shibeshi, "In vivo antidiarrheal and ex vivo spasmolytic activities of the aqueous extract of the roots of E. kebericho Mesfin (Asteraceae) in rodents and isolated guinea pig ileum," International Journal of Pharmacy and Pharmacology, vol. 2, no. 7, pp. 110-116, 2013.

[49] A. Toma, S. Deyno, A. Fikru, A. Eyado, and A. Beale, "In vivo antiplasmodial and toxicological effect of crude ethanol extract of Echinops kebericho traditionally used in treatment of malaria in Ethiopia," Malaria Journal, vol. 14, no. 1, p. 196, 2015.

[50] R. Garner, E. Clarke, and M. L. Clarke, "Lander's Veterinary Toxicology," Harcourt Publishers, London, 1977.

[51] D. Abdeta, N. Kebede, M. Giday, G. Terefe, and M. A. Abay, "In vitro and in vivo antitrypanosomal activities of methanol extract of E. kebericho roots," Evidence-based Complementary and Alternative Medicine, vol. 2020, 2019. 